\title{
Predictor Accuracy of Absolute Neutrophil Count in Early Onset Sepsis
}

\author{
Nirav S. Panchal and Bipin H. Chavda* \\ Dept. of Pathology, GMERS Medical college, Gandhinagar. Gujarat - 382016. India.
}

\section{ABSTRACT}

Background: The most important causes of mortality in infants are sepsis, prematurity, low birth weight, birth trauma and neonatal asphyxia. Absolute neutrophil count is faster, easier, cheaper and simpler laboratory parameter to be used for prediction of early onset sepsis. This study is aimed to measure the influence of change in the absolute neutrophil count on babies born to mothers having risk factors for infection.

Methods: Design of the study was cohort prospective model. Total 123 patients were included in the study after considering appropriate inclusion criteria. The patients were divided into 3groups: ANC(Absolute neutrophil count) $<1800 / \mathrm{cmm}$, ANC 1800-5399/cmm and ANC > 5400/cmm. Results were analysed by GraphpadInstat Demo.

Results: New born to mothers having risk factors for sepsis with high ANC $(>5400 / \mathrm{cmm})$ and normal ANC (1800-5399/cmm) shows a significant difference with $\mathrm{p}=0.000(\mathrm{p}<0.05)$; Odds ratio 9.35 , sensitivity $82.8 \%$, specificity $65.9 \%$, positive predictive value $79.4 \%$ and negative predictive value $70.7 \%$.

Conclusion: Incidence of early onset sepsis is 9.35 times higher in new borns born to mothers with risk factors for sepsis having higher ANC (particularly $>10000 / \mathrm{cmm}$ ) than those having ANC level within normal limits.

Keywords: Early Onset Sepsis, Absolute Neutrophil Count

\section{Introduction}

Neonatal mortality is considered as a country's primary health status indicator. ${ }^{1}$ Around one million children die every year in India before completing their first month of life. The common causes of neonatal deaths in India include infections, birth asphyxia, and prematurity which contribute to $32.8 \%, 22.3 \%$, and $16.8 \%$ of the total neonatal deaths, respectively. ${ }^{2}$ Approximately $41 \%$ of all under 5 year child deaths happen in the first week of life and the risk of deaths during neonatal period is at least 68 times higher than the rest of childhood. ${ }^{3}$ Infection which occurs during foetal life or during delivery is classified as Early Onset Sepsis and that occur after birth is classified as Late Onset Sepsis.

Considering limited supportive resources at most places of the country, a simpler, cheaper, easier and faster laboratory test parameter which helps to predict the development of sepsis and helps the clinicians to diagnose timely and treat the neonatal sepsis is required. This study determines the influence of the change in ANC (Absolute neutrophil count) on early neonatal sepsis. Study is designed to assess the accuracy of ANC in predicting early onset sepsis.

\section{Material and Methods}

This is a cohort prospective study carried out from December 2014 to February 2017 at one of the private hospitals in North Gujarat. Study populations include babies born to mothers having risk factors for infection. Inclusion criteria for study population were: new born, single birth (not showing clinical signs and symptoms directing towards sepsis), born to mothers having $>$ or $=$ 2 risk factors for infection (fever $>38 \mathrm{C}$, Total leukocyte count $>15000 / \mathrm{cmm}$, Amniotic fluid - Meconium stained or not clear otherwise, Premature rupture of membranes $>18$ hours). Newborns a)born with congenital anomalies b) received resuscitation or undergone any invasive procedures after birth c) received antibiotics prior to blood sample collection d) born to mothers with co morbid disease excluding risk factor for sepsis were not included in the study. Venous blood samples were collected from the patients and stored immediately. Samples were analyzed by automatic blood analyzer (Nihon Kohden).

Early onset sepsis is defined as a clinical syndrome manifested in first 72 hours of life. It is often caused by invasion of microorganisms into the blood stream. Diagnosis of neonatal sepsis was established if the newborn have $\geq 2$ Category A OR $\geq 3$ Category B manifestations (Table 1).

The ANC were counted by multiplying total of mature neutrophil and band neutrophil percentage with total leukocyte count/cmm. The ANC was considered high when 
$>5400 / \mathrm{cmm}$, low when $<1800 / \mathrm{cmm}$ and normal when $1800-5400 / \mathrm{cmm}$. Thus, subject population was divided into three categories based on their ANC.

Statistical analysis was performed by GraphpadInStat Demo [DATASET1.ISD] software. Sensitivity, specificity, positive predictive value, negative predictive value, odds ratio and $\mathrm{p}$ value were calculated.

\section{Results}

Total 123 samples were assessed in the study. Table 2 shows divisions of samples with respect to different sample characteristics (which were used as inclusion criteria) and their impact on the outcomes. It was found that difference in the mean value of high ANC between EOS group and nEOS group was statistically significant (Table 3 ). There is also a statistically very much significant difference for occurrence of early onset sepsis between high ANC $(>5400 / \mathrm{cmm})$ and normal ANC (1800-5399/cmm) group with $\mathrm{p}$ value $0.000(\mathrm{p}<0.005)$. Other statistical parameters were also calculated to determine the effectiveness of ANC in prediction of early onset sepsis. They are as follows: Sensitivity $=82.9 \%$, specificity $=65.9 \%$, positive predictive value $=79.4 \%$ and negative predictive value $=$ $70.7 \%$. Odds ratio was 9.35 which signifies that group with $\mathrm{ANC}>5400 / \mathrm{cmm}$ has 9.35 times higher risk of developing EOS than the group with ANC $<5400 / \mathrm{cmm}$ (Table 4).

Table 1: Clinical Signs and Symptoms for Diagnosing Early Onset Sepsis

\begin{tabular}{|c|c|}
\hline Category A & Category B \\
\hline Respiratory distress & Tremor \\
\hline Seizure & Lethargy or weakness \\
\hline Unconsciousness & Irritable \\
\hline Temperature instability & Vomiting \\
\hline Deterioration of vitals & Distended abdomen \\
\hline & Decreased activity \\
\hline & Not drinking well, previously well \\
\hline
\end{tabular}

Table 2: Sample population characteristics

\begin{tabular}{|c|c|c|c|c|c|}
\hline \multirow[t]{2}{*}{ Characteristics } & \multicolumn{3}{|c|}{ Outcome } & \multirow[t]{2}{*}{ Total (No.) } & \multirow[t]{2}{*}{$P$ value } \\
\hline & & EOS (No.) & No EOS (No.) & & \\
\hline \multirow[t]{2}{*}{ Sex } & Male & 39 & 25 & 64 & \multirow{2}{*}{0.348} \\
\hline & Female & 31 & 28 & 59 & \\
\hline \multirow{2}{*}{$\begin{array}{c}\text { Maternal } \\
\text { Temperature }\end{array}$} & Fever & 34 & 24 & 58 & \multirow{2}{*}{0.718} \\
\hline & No fever & 36 & 29 & 65 & \\
\hline \multirow{2}{*}{$\begin{array}{c}\text { Maternal } \\
\text { leukocytosis }\end{array}$} & Present & 41 & 29 & 70 & \multirow{2}{*}{0.669} \\
\hline & Absent & 29 & 24 & 53 & \\
\hline \multirow{2}{*}{$\begin{array}{l}\text { Premature } \\
\text { rupture of } \\
\text { membrane }\end{array}$} & Yes & 34 & 30 & 64 & \multirow{2}{*}{0.377} \\
\hline & No & 36 & 23 & 59 & \\
\hline \multirow{2}{*}{ Amniotic Fluid } & Clear & 32 & 33 & 65 & \multirow{2}{*}{0.07} \\
\hline & Not Clear & 38 & 20 & 58 & \\
\hline
\end{tabular}

Table 3: Mean of High ANC ( $>5400 / \mathrm{cmm})$

\begin{tabular}{|c|c|c|}
\hline & \multicolumn{2}{|c|}{ Outcome } \\
\hline Mean & EOS & 7864 \\
\hline SD & 13546 & 2418 \\
\hline Range & 5078 & $5530-12930$ \\
\hline
\end{tabular}


Table 4: Association between high ANC and normal ANC on the outcome

\begin{tabular}{|c|c|c|c|}
\hline \multirow{2}{*}{ ANC } & \multicolumn{2}{|c|}{ Outcome } & \multirow{2}{*}{ Total (No.) } \\
\cline { 2 - 4 } & EOS (No.) & nEOS (No.) & 73 \\
\hline$>5400 / \mathrm{cmm}$ & 58 & 15 & 41 \\
\hline $1800-5399 / \mathrm{cmm}$ & 12 & 29 & $\mathbf{1 1 4}$ \\
\hline Total & $\mathbf{7 0}$ & $\mathbf{4 4}$ & \\
\hline
\end{tabular}

\section{Discussion}

Baby can be exposed to infection in utero, during delivery or after birth. Infection can be viral, bacterial or fungal but it is the bacterial infection which plays crucial role in neonatal sepsis. To get rid of this bacterial infection, neutrophils are released into circulation from bone marrow which then migrates to the site of infection to phagocytose the organisms. As a result, there will be rise in the neutrophil count. However, studies have shown that neonatal bone marrow has lesser reserve for neutrophil, which leads to neutropenia and immature neutrophils can be seen in peripheral circulation. ${ }^{4}$ Monroe et al. have shown that Streptococcus group B infection produces neutropenia in peripheral circulation and granulocyte depletion in bone marrow in neonate. ${ }^{5}$ However, research done by Bhandari et al. shows that new born that have sepsis have higher ANC levels than those without sepsis. ${ }^{6}$

Currently, gold standard for diagnosing neonatal sepsis is blood culture. But however, it is time consuming as it takes 3 to 5 days for results to come. So delay in diagnosis put threats on baby's survival. Moreover, positive or negative blood culture results may be found in case of contamination or some common bacterial infection. Other parameter used, C-reactive protein, is found to be elevated in cases of neonatal sepsis. But it is also found to be elevated in non-infectious organ damage and certain non-infectious respiratory diseases. 7, 8 Newer parameters like Cd64, Serum levels of Mannose Binding Lectin, Procalcitonin and Interleukin- 6 have also been introduced for detection of early onset sepsis. Study showing inter parameter comparison has also been performed..$^{9}$ But however, all these test parameters require advanced laboratory technology and it is costly. Therefore, a study to determine the effectiveness of ANC to predict early onset sepsis is important to perform.

Several studies have established association between high ANC and early onset sepsis but area to determine effectiveness of ANC as a prognostic parameter or in predicting the occurrence of early onset sepsis has still been not looked into. There were total 123 patients were included in the study. 58 patients had history of maternal fever while 65 patients did not have with $\mathrm{p}$ value 0.718 (p
$>0.05)$. Maternal leukocytosis was present in 70 patients while absent in 53 patients with $\mathrm{p}$ value $0.669(\mathrm{p}>0.05)$. There were 65 patients with clear amniotic fluid while it was not clear in remaining 58 patients with p value 0.07 ( $\mathrm{p}>$ $0.05)$. Similarly, the $\mathrm{p}$ value for the characteristic premature rupture of membrane was $0.377(\mathrm{p}>0.05)$ (Table 2).

In group having high ANC level ( $>5400 / \mathrm{cmm})$, occurrence of early onset sepsis is 9.35 times greater than its peer group with normal ANC level (1800-5399/cmm) with $p$ value $0.000(p>0.05)$. This result is similar with the results of Bhandari et al. which also suggested that level of ANC is higher in new borns having EOS as compare to the new borns not having EOS. ${ }^{6}$ From table 3 it is evident that in EOS group high ANC has median of 13546/ $\mathrm{cmm}$ with range of $5420-30470 / \mathrm{cmm}$ (SD: $5078 / \mathrm{cmm}$ ), whereas in nEOS group high ANC has median of 7864/ $\mathrm{cmm}$ with range of 5530-12930/cmm (SD: $2418 / \mathrm{cmm}$ ). The difference between these two is statistically significant at $\mathrm{p}<0.05$. This result is also in consistent with results of study conducted by Bhandari et al. which also shows that group of EOS babies show higher median for ANC as compared to nEOS babies with $\mathrm{p}<0.05$. The results are also in similarity with other studies conducted by Frakking et al., Mohammed et al., Dzwonek et al. and Schlapbach et al. which also suggested that association of high ANC with the occurrence of early onset sepsis is statistically significant. ${ }^{6,10-13}$

From table 4 it is also evident that there are also some cases of EOS occurred at normal ANC level (1800-5399/cmm) and some cases with high ANC level $(>5400 / \mathrm{cmm})$ did not develop EOS. Still higher ANC level has good sensitivity and specificity to give us a lead about early onset sepsis. Out of 70 EOS patients 05 were having ANC $<5400 / \mathrm{cmm}$. From the remaining EOS patients having higher $\mathrm{ANC}$, majority of them were having ANC level more than 10000/ $\mathrm{cmm}$. This result is similar with the previous studies which showed that new borns having high ANC are at high risk for developing neonatal sepsis. This prediction is more likely to be true in babies born to mothers having risk factors for infection. ${ }^{11-13}$

This study can be used as a predictor for the occurrence of early onset sepsis in new born babies of the mothers 
with sepsis risk factors and thus for the innovation in the new born management. This study forms the ground for routine ANC examination in new born from mother with the infection risk factor. So, if the ANC level is high (particularly $>10000 / \mathrm{cmm}$ ) then baby should be closely monitored and if associated with clinical signs and symptoms treatment should be promptly started. This will prevent delay in treatment and hence will help to decrease the morbidity and mortality in new born related to sepsis.

\section{Conclusion}

Design of the study is cohort prospective which is best to determine the course of the disease and to explain the association between exposure and outcome. Therefore, final results of this study can also be utilised for adding $\mathrm{ANC}$ as one of the diagnostic criteria for early onset sepsis particularly in new borns born to the mothers having risk factors for sepsis and to re-evaluate the management in such patients to decrease morbidity and mortality related to early onset sepsis.

\section{Acknowledgements}

We are grateful to all the hospital staff particularly Dr. Divyesh Shah and technical staff without whose support it was not possible to conduct the study.

\section{Abbreviations}

EOS (early onset sepsis), nEOS (not having early onset sepsis), ANC (Absolute neutrophil count).

No funding was received for the study.

There is no any conflict of interests.

\section{References}

1. Sudarianto, Mursalim, Nur M, Syahrir, Nurmiyati, Haruna I., et al. Health profile of South Sulawesi 2008. Public Health Office of South Sulawesi. 2009: (1).

2. Upadhyay RP, Chinnakali P, Odukoya O, Yadav K, Sinha S, Rizwan SA, et al. High Neonatal Mortality Rates in Rural India: What Options to Explore? ISRN
Paediatrics Volume 2012, Article ID 968921. http://dx.doi. org/10.5402/2012/968921.

3. Lahariya C, Paul VK. Burden, differentials and causes of child deaths in India. Indian J Pediatr, 2010, 77(11), 13121321.

4. Burgner D, Strunk T. Genetic Susceptibility to Neonatal Infection. Department of Neonatal Paediatrics. Australia. 2006, 19(3): 259-63.

5. Schmutz N, Henry E, Jopling J, Christensen D. Expected ranges for blood neutrophil concentrations of neonates: The Manroe and Mouzinho charts revisited. J Perinatol. 2008, 28(4): 275-81.

6. Bhandari V, Wang C, Rinder C, Rinder H. Hematologic profile of sepsis in neonates: neutrophil $\mathrm{Cd} 64$ as a diagnostic marker. Pediatrics. Jan 2008, 121(1):129-34..

7. Bellig L, Ohning, B. Neonatal sepsis. http://emedicine. medscape.com/article/978352-overview. 2014.

8. Anwer K, Mustafa S. Rapid identification of neonatal sepsis. J Pak Med Assoc. 2000 Mar; 50(3): 94-8.

9. Resch B, Gusenleitner W, Muller WD. Procalcitonin and interleukin-6 in the diagnosis of Early onset sepsis of the neonate. Acta Paediatrica: Nurturing the child. Jan 2007. https://doi.org/10.1111/j.1651-2227.2003.tb00534.x

10. Frakking FN, Brouwer N, Eijkelenburg NK, Merkus MP, Kuijpers TW, Offringa M., et al. Low mannose-binding lectin (MBL) levels in neonates with pneumonia and sepsis. British society for immunology, Clinical and Experimental Immunology. 2007; 150: 255-62.

11. Wahab Mohamed WA, Saeed MA. Mannose-binding lectin serum levels in neonatal sepsis and septic shock. J Matern Fetal Neonatal Med. 2012 Apr, 25(4):411-4.

12. Dzwonek AB, Neth OW, Thiebaut R, Gulczynska E, Chilton M, Hellwig T. The role of mannose-binding lectin in susceptibility to infection in preterm neonates. Pediatric Research, 2008, 63(6):680.

13. Schlapbach LJ, Mattmann M, Thiel S, Boillat C, Otth M, Nelle M., et al. Differential role of the lectin pathway of complement activation in susceptibility to neonatal sepsis. Clinical Infectious Diseases, July 2010, 51(2):153-162.

*Corresponding author:

Dr. Bipin H. Chavda, 102, Teaching staff quarter (Doctor’s Quarters), Nr. P. G. Hostel, Civil Hospital Campus, Sector-12B,

Gandhinagar, Gujarat - 382016. India.

Phone: +91963808 1988 .

Email: drbipin121@gmail.com

Financial or other Competing Interests: None. 